\title{
Current epidemiology of tetanus in England, 2001-2014
}

\author{
S. COLLINS ${ }^{1}$, G. AMIRTHALINGAM ${ }^{1}$, N. J. BEECHING ${ }^{2}$, M. A. CHAND ${ }^{3,4}$, \\ G. GODBOLE ${ }^{3}$, M. E. RAMSAY ${ }^{1}$, N. K. FRY ${ }^{5}$ AND J. M. WHITE ${ }^{1}$ \\ ${ }^{1}$ Immunisation, Hepatitis and Blood Safety Department (IHBSD), Public Health England, London, UK \\ ${ }^{2}$ Tropical and Infectious Disease Unit, Royal Liverpool University Hospital; Clinical Science Group, Liverpool \\ School of Tropical Medicine; and National Institute for Health Research Health Protection Research Unit in \\ Emerging and Zoonotic Infections, University of Liverpool, Liverpool, UK \\ ${ }^{3}$ Microbiology Services, Public Health England, London, UK \\ ${ }^{4}$ Department of Infectious Diseases, Guy's \& St Thomas' NHS Foundation Trust, London, UK \\ ${ }^{5}$ Respiratory and Vaccine Preventable Bacteria Reference Unit (RVPBRU), Public Health England, London, \\ $U K$
}

Received 16 December 2015; Final revision 28 May 2016; Accepted 1 June 2016;

first published online 18 August 2016

\section{SUMMARY}

Public Health England conducts enhanced national surveillance of tetanus, a potentially lifethreatening vaccine-preventable disease. A standardized questionnaire was used to ascertain clinical and demographic details of individuals reported with clinically suspected tetanus. The 96 cases identified between 2001 and 2014 were analysed. The average annual incidence was $0 \cdot 13 /$ million $(95 \%$ confidence interval $0 \cdot 10-0 \cdot 16)$ of which $50 \cdot 0 \%$ were male. Where reported, $70 \cdot 3 \%$ of injuries occurred in the home/garden (45/64). Overall, 40.3\% (31/77) cases were in people who inject drugs (PWID), including a cluster of 22 cases during 2003-2004. Where known $(n=68)$, only $8 \cdot 8 \%$ were age-appropriately immunized. The overall case-fatality rate was $11 \cdot 0 \%(9 / 82)$. All tetanus-associated deaths occurred in adults aged $>45$ years, none of whom were fully immunized. Due to the success of the childhood immunization programme, tetanus remains a rare disease in England with the majority of cases occurring in older unimmunized or partially immunized adults. Minor injuries in the home/garden were the most commonly reported likely sources of infection, although cases in PWID increased during this period. It is essential that high routine vaccine coverage is maintained and that susceptible individuals, particularly older adults, are protected through vaccination and are offered timely post-exposure management following a tetanus-prone wound.

Key words: Epidemiology, outcome, tetanus, vaccination.

\section{INTRODUCTION}

Tetanus is a potentially life threatening disease caused by the neurotoxin produced by the spore-forming,

\footnotetext{
* Author for correspondence: Ms. S. Collins, National Infection Service, Immunisation, Hepatitis, and Blood Safety Department, Public Health England, 61Colindale Avenue, London NW9 5EQ, UK. (Email: sarah.collins@phe.gov.uk)
}

Gram-positive, bacillus Clostridium tetani. C. tetani is widespread in the environment, where it exists for long periods in the form of spores and is frequently found in soil [1]. The disease occurs when tetanus spores contaminate a wound, germinate and multiply producing tetanus toxin. The toxin enters peripheral motor neurons and is transported to the central nervous system where it blocks the release of inhibitory 
neurotransmitters such as GABA, resulting in a characteristic spastic paralysis. Tetanus is not transmitted via person-to-person contact; therefore, individuals need to rely on direct protection through immunization as there is no 'herd immunity'. Commonly reported routes of transmission include puncture wounds and injecting drug use [2, 3]; however, tetanus can be transmitted through minor injuries [4]. In resource-poor settings, contamination of the umbilical stump continues to be an important but preventable cause of neonatal tetanus [5].

There is a safe and effective vaccine against tetanus which was introduced into the UK routine childhood vaccination programme in 1961 [6]. Prior to this the Armed Forces have provided tetanus vaccination to service personnel since 1938 [6]. In England the current immunization schedule consists of accelerated primary immunization with diphtheria, tetanus, pertussis, polio and Haemophilus influenzae type b (DTaP/IPV/Hib) vaccine given at ages 2, 3 and 4 months, with two further booster doses of tetanus-containing vaccine given at around 3 years and 4 months or soon after, and around 14 years [7]. Since 1990, coverage of tetanus vaccination at age 2 years has been between $94 \%$ and $96 \%$ [8]. This consistently high level of vaccine coverage has reduced the pool of susceptible individuals in children and young adults as demonstrated by recent seroprevalence studies [9]. Diagnosis of tetanus is primarily based on clinical presentation, with laboratory results used to help support the diagnosis [1].

Public Health England (PHE) is responsible for the national surveillance of vaccine-preventable diseases. As cases of tetanus are rare, enhanced surveillance is carried out by the Immunization, Hepatitis and Blood Safety Department. Here we describe the changing epidemiology of tetanus in England during the 14-year period 2001-2014 inclusive.

\section{METHODS}

\section{Surveillance}

During 2001-2014, the identification of suspected tetanus cases was carried out using multiple data sources. Tetanus is a notifiable disease in England under the Public Health (Control of Disease) Act 1984 and the Health Protection (Notification) Regulations 2010, which impose a statutory duty on doctors and laboratories to report suspected cases or relevant microbiological isolates to a 'proper officer', usually the Health Protection Team (HPT) [10]. Once a suspect case is identified, PHE provides quantitation of antibody to tetanus toxoid in serum [11], detection of tetanus neurotoxin in serum by animal bioassay and detection, isolation and identification of $C$. tetani in wound material by polymerase chain reaction and culture. These laboratory services can provide information to support the clinical diagnosis and are provided alongside specialist clinical advice if required, including the use of specific or human normal immunoglobulins, following national recommendations [12, 13]. PHE receives notification of cases from statutory notifications, from clinical enquires, and samples sent to Microbiology Services. Death registrations from the Office of National Statistics (ONS) were used to identify any additional unreported cases and case fatalities [14].

As part of the enhanced surveillance each case of suspected clinical tetanus was followed up to determine additional demographic, risk factors, and clinical information from a range of sources including the reporting clinician, general practice, and local HPTs, using a standardized questionnaire to ensure consistency. Where possible the final outcome of the case and any long-term sequelae were recorded. Cases for which an initial diagnosis of clinical tetanus was subsequently ruled out by the patient's clinician were excluded from analysis.

\section{Hospital Episode Statistics (HES) data matching}

Anonymized HES for all hospital admissions in England coded with an ICD-10 diagnostic code for tetanus, obstetric tetanus, or tetanus neonatorum (A33-A35) are published by fiscal years and data were obtained for 2000/2001 to 2010/2011 [15]. Multiple hospital episodes for one individual were counted as one case and the total length of admission calculated. Cases were reviewed by a senior clinical scientist and consultant to eliminate records which were clearly miscoded as tetanus.

Cases of tetanus from the HES dataset were matched to the enhanced surveillance dataset based on a combination of age, gender, ethnicity, admission date, discharge date, and region.

\section{Analysis}

Data were managed using MS Access and MS Excel (Microsoft Corp., USA), and statistical tests were performed using Stata v. 12 (StataCorp., USA). A case was classified as being age-appropriately immunized if they had received the recommended number of doses of tetanus-containing vaccine, those with fewer 
than the recommended number of doses were classified as being partially immunized [7]. The Ablett classification was used to grade the severity of tetanus [16]. Differences between groups were assessed using $\chi^{2}$ or Fisher's exact tests. Incidence rates with $95 \%$ Poisson confidence intervals were calculated using the 2006 mid-year population estimate published by ONS [14]. Trends in the number of notifications and deaths over time were assessed using a generalized linear model with Poisson regression to compensate for overdispersion. Differences in incidence were assessed using univariate and multivariate Poisson regression where the largest group was taken as the baseline (males, aged $\geqslant 65$ years, and the North West region). Prevalence of injecting drug use was based on 2006 Home Office data [17]. Childhood vaccination coverage was based on data collected and published through the COVER programme, which reports on the percentage of children immunized by their first, second or fifth birthday [18].

\section{Ethical approval}

PHE has legal permission, provided by Regulation 3 of The Health Service (Control of Patient Information) Regulations 2002, to process patient confidential information for national surveillance of communicable diseases (http://www.legislation.gov. uk/uksi/2002/1438/regulation/3/made). This includes PHE's responsibility to monitor the safety and effectiveness of vaccines.

\section{RESULTS}

\section{National surveillance}

Since 1969, the proportion of the population completing a primary course of vaccine against tetanus has increased, with coverage in England at age 2 years between $94 \%$ and $96 \%$ since 1990 (Fig. 1). The number of tetanus notifications decreased by $4.5 \%$ year on year [incidence rate ratio (IRR) $0 \cdot 955,95 \%$ confidence interval (CI) 0.947-0.962, $P<0 \cdot 01$ ] from 19 in 1969 to four in 2014 (Fig. 1). The number of tetanus-related deaths also decreased by $6.0 \%$ year on year (IRR $0.940,95 \%$ CI $0.922-0.954, P<0.01)$ in the same period (Fig. 1). Since the establishment of a national enhanced surveillance programme in 1984, 268 cases of clinical tetanus have been recorded.

During 2001-2014, 96 cases of tetanus in England were reported to PHE through the procedures already described (range 3-21 cases/year) (Fig. 1), 43 (44.8\%) of these cases were formally notified. The average annual incidence of tetanus was $0 \cdot 13 /$ million population (95\% CI $0 \cdot 11-0 \cdot 16$, range $0 \cdot 06-0 \cdot 42)$. The highest annual incidence was recorded in $2004(0.42 /$ million, 95\% CI $0 \cdot 26-0 \cdot 64)$. However, this was during an increase in tetanus specifically in people who inject drugs (PWID) and after excluding these 13 cases, the incidence reduced to $0 \cdot 16 /$ million $(95 \%$ CI $0 \cdot 07$ $0 \cdot 31$ ) comparable to other years.

Slight variations in the overall number of reported cases by region were observed (range 2-14 cases) (Table 1). The highest average annual incidence was in the East Midlands ( $0 \cdot 18$ /million, 95\% CI 0.09-0.32, $P=0.446$ ), whereas the lowest was in the North East (0.06/million, 95\% CI $0 \cdot 01-0 \cdot 20, P=0 \cdot 490)$.

There was no gender difference in reported cases (50.0\% males) (Table 2$)$ and although the overall incidence of tetanus in males $(0 \cdot 14 /$ million, $95 \%$ CI $0 \cdot 10$ $0 \cdot 18$ ) was slightly higher than the incidence in females $(0 \cdot 13 /$ million, $95 \%$ CI $0 \cdot 10-0 \cdot 18, P=0 \cdot 929)$, this was not significant with or without adjustment by age group (Table 2). Nearly half of all cases of tetanus were in those born after routine childhood immunization was introduced $(45 / 96,46 \cdot 9 \%)$. Few cases of tetanus were reported in children aged $<16$ years $(n=$ 4 ), with no cases reported in children aged $<5$ years (Table 2). The median age of cases was 48.0 [interquartile range (IQR) 33.5-75.0] years. Males (median $46 \cdot 0$, IQR $30 \cdot 5-59 \cdot 5$ years) were on average 11.5 years younger than females (median 57.5, IQR $35 \cdot 0-79 \cdot 5$ years, $P=0 \cdot 216$ ). Excluding all 31 cases in PWID increased the median age to $61 \cdot 0$ years (IQR $41-80$ years; $z=4.69, P<0.001)$ and the difference between the median age of males and females increased to 21 years [males: $55 \cdot 0$ (IQR 33-74) vs. females: 76 years (IQR 44-82); $z=2 \cdot 36, P=0 \cdot 018$ ). Incidence varied by age group; the highest incidence was observed in case-patients aged $>64$ years $(0 \cdot 27 /$ million, $95 \%$ CI $0 \cdot 19-0 \cdot 39)$.

\section{Additional case information}

Enhanced surveillance forms were received for $95.8 \%(n=92)$ of cases, which includes additional information on immunization status, risk exposure, post-exposure therapy, and severity of disease recorded (Table 3).

\section{Immunization status}

Immunization status at the time of injury was known for $70 \cdot 8 \%(68 / 96)$ of cases. Where known, few $(n=6$, 


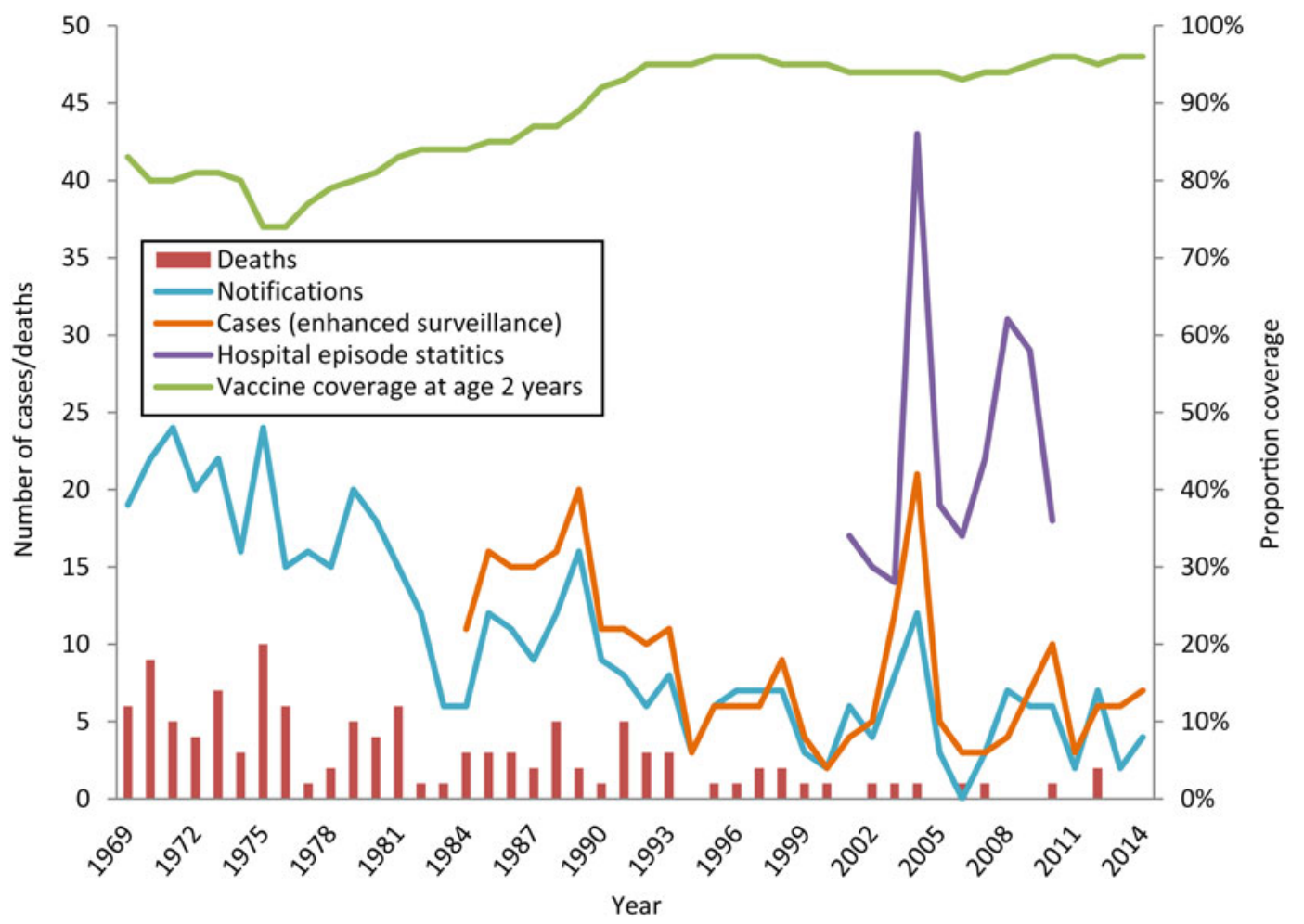

Fig. 1. Tetanus cases, deaths and vaccine coverage in England, 1969-2014 (tetanus became a notifiable disease in 1969).

Table 1. Average annual incidence of tetanus by country and region, 2001-2014

\begin{tabular}{|c|c|c|c|c|}
\hline Region & No. of cases & $\begin{array}{l}\text { Average annual } \\
\text { incidence/106 } \\
\text { pop. }(95 \% \mathrm{CI})\end{array}$ & $\begin{array}{l}\text { No. of cases } \\
\text { in PWID }\end{array}$ & $\begin{array}{l}\text { Average annual } \\
\text { incidence in PWID } / 10^{6} \\
\text { PWID pop. }(95 \% \mathrm{CI})\end{array}$ \\
\hline England & 96 & $0 \cdot 14(0 \cdot 11-0 \cdot 16)$ & 31 & $14 \cdot 96(10 \cdot 16-21 \cdot 23)$ \\
\hline East Midlands & 11 & $0 \cdot 18(0 \cdot 09-0 \cdot 32)$ & 4 & $37 \cdot 39(10 \cdot 19-95 \cdot 73)$ \\
\hline East of England & 9 & $0 \cdot 11(0 \cdot 05-0 \cdot 22)$ & 1 & $4 \cdot 67(0 \cdot 12-26 \cdot 01)$ \\
\hline London & 14 & $0 \cdot 13(0 \cdot 07-0 \cdot 22)$ & 4 & $15 \cdot 61(4 \cdot 25-39 \cdot 97)$ \\
\hline North East & 2 & $0 \cdot 06(0 \cdot 01-0 \cdot 20)$ & 1 & $7.89(0.20-43 \cdot 94)$ \\
\hline North West & 14 & $0 \cdot 15(0 \cdot 08-0 \cdot 24)$ & 7 & $22 \cdot 40(9 \cdot 01-46 \cdot 15)$ \\
\hline South Central & 10 & $0 \cdot 18(0 \cdot 09-0 \cdot 33)$ & 2 & $22 \cdot 49(2 \cdot 72-81 \cdot 25)$ \\
\hline South East Coast & 8 & $0 \cdot 13(0 \cdot 06-0 \cdot 27)$ & 2 & $18 \cdot 62(2 \cdot 25-67 \cdot 26)$ \\
\hline South West & 12 & $0 \cdot 17(0 \cdot 09-0 \cdot 29)$ & 4 & $15 \cdot 96(4 \cdot 35-40 \cdot 87)$ \\
\hline West Midlands & 10 & $0 \cdot 13(0 \cdot 06-0 \cdot 24)$ & 5 & $23.98(7 \cdot 79-55 \cdot 96)$ \\
\hline Yorkshire and the Humber & 6 & $0 \cdot 08(0 \cdot 03-0 \cdot 18)$ & 1 & $3 \cdot 29(0 \cdot 08-18 \cdot 31)$ \\
\hline
\end{tabular}

CI, Confidence interval; PWID, people who inject drugs.

$8 \cdot 8 \%$ ) were appropriately immunized for their age, a further $50 \cdot 0 \%$ were partially immunized and $41 \cdot 2 \%$ were unimmunized (Table 3). Immunization status was known for $71 \cdot 1 \%(32 / 45)$ of cases born in or after 1961, and therefore eligible for routine childhood immunization, $18.8 \% \quad(n=6)$ were age-appropriately immunized, a further $59 \cdot 4 \%(n=19)$ were partially immunized, and $21.9 \% \quad(n=7)$ were unimmunized. There was no significant difference in the vaccination status of males compared to females in this group $\left(\chi^{2}\right.$ $=0 \cdot 1118, P=0.943$ ).

Of those born prior to 1961, immunization status was known for $76.6 \%(36 / 47)$; none of this group had received five doses of a tetanus-toxoid-containing vaccine, $58 \cdot 3 \%(n=21)$ were unimmunized and $41 \cdot 7 \%$ $(n=15)$ were partly immunized; gender was not statistically significant $\left(\chi^{2}=0.538, \quad P=0.463\right)$. Using ordered logistic regression older case-patients had 
Table 2. Average annual incidence of tetanus by age group and sex, 2001-2014

\begin{tabular}{|c|c|c|c|c|c|c|}
\hline \multirow[b]{2}{*}{$\begin{array}{l}\text { Age } \\
\text { group, } \\
\text { years }\end{array}$} & \multicolumn{2}{|l|}{ Females } & \multicolumn{2}{|l|}{ Males } & \multicolumn{2}{|l|}{ Total } \\
\hline & $\begin{array}{l}\text { No. of } \\
\text { cases } \\
\text { (PWID) }\end{array}$ & $\begin{array}{l}\text { Average annual } \\
\text { incidence } / 10^{6} \text { pop. } \\
(95 \% \mathrm{CI})\end{array}$ & $\begin{array}{l}\text { No. of } \\
\text { cases } \\
\text { (PWID) }\end{array}$ & $\begin{array}{l}\text { Average annual } \\
\text { incidence } / 10^{6} \text { pop. } \\
(95 \% \mathrm{CI})\end{array}$ & $\begin{array}{l}\text { No. of } \\
\text { cases } \\
\text { (PWID) }\end{array}$ & $\begin{array}{l}\text { Average annual } \\
\text { incidence } / 10^{6} \text { pop } \\
(95 \% \mathrm{CI})\end{array}$ \\
\hline $0-4$ & - & - & - & - & - & - \\
\hline $5-14$ & $1(0)$ & $0 \cdot 02(0 \cdot 00-0 \cdot 13)$ & $3(-)$ & $0 \cdot 07(0 \cdot 01-0 \cdot 20)$ & $4(-)$ & $0 \cdot 05(0 \cdot 01-0 \cdot 12)$ \\
\hline $15-24$ & $4(4)$ & $0 \cdot 09(0 \cdot 02-0 \cdot 22)$ & $3(1)$ & $0 \cdot 06(0 \cdot 01-0 \cdot 18)$ & $7(5)$ & $0 \cdot 07(0 \cdot 03-0 \cdot 15)$ \\
\hline $25-44$ & $14(6)$ & $0 \cdot 14(0 \cdot 08-0 \cdot 23)$ & $17(12)$ & $0 \cdot 17(0 \cdot 10-0 \cdot 27)$ & $31(18)$ & $0 \cdot 15(0 \cdot 10-0 \cdot 22)$ \\
\hline $45-64$ & $9(3)$ & $0 \cdot 10(0 \cdot 05-0 \cdot 19)$ & $14(5)$ & $0 \cdot 16(0 \cdot 09-0 \cdot 27)$ & $23(8)$ & $0 \cdot 13(0 \cdot 08-0 \cdot 20)$ \\
\hline$\geqslant 65$ & $20(-)$ & $0 \cdot 31(0 \cdot 19-0 \cdot 48)$ & $11(-)$ & $0 \cdot 22(0 \cdot 11-0 \cdot 40)$ & $31(-)$ & $0 \cdot 27(0 \cdot 19-0 \cdot 39)$ \\
\hline Total & $48(13)$ & $0 \cdot 13(0 \cdot 10-0 \cdot 18)$ & $48(18)$ & $0 \cdot 14(0 \cdot 10-0 \cdot 18)$ & $96(31)$ & $0 \cdot 14(0 \cdot 11-0 \cdot 16)$ \\
\hline
\end{tabular}

CI, Confidence interval; PWID, people who inject drugs.

decreased vaccination status but this was not statistically significant with or without adjustment for gender $(P=0 \cdot 072$ and $P=0 \cdot 079$, respectively).

\section{Risk exposure}

Of the 81 cases with available risk exposure data, $90 \cdot 2 \%(n=73)$ had a history of injury prior to the onset of tetanus and $9.9 \%(n=8)$ had no known signs of injury (Table 3 ).

Of those injured the setting was unknown for $11 \cdot 1 \%$ (9/73) of cases. Where known, the most frequent setting for injury was in the home or garden $(70 \cdot 3 \%$, 45/64). A further eight cases injured themselves in a park, woodland, or rural setting, three were injured in the street or road, two were injured at work, and six were injured in other settings. Of the six casepatients with other injuries, four were PWID who were injecting at a number of different injection sites, one was assaulted while abroad, and one individual fell from a height onto grass.

Puncture wounds were the most common type of injury $(49 \cdot 3 \%, 36 / 73), 21$ of which were due to injection site injuries in PWID. A further 29 cases sustained lacerations, five were bitten or scratched by animals, three had non-healing wounds (two with diabetic ulcers, one with a burn).

Comparatively few case-patients had both a known date of injury and date of onset $(n=25)$. Where known, onset of symptoms was on average 6 days post-injury (range $0-13$ days).

\section{Treatment}

Details of treatment at the time of injury were known for 55 cases (Table 3); where known, 29\% (16/55) received medical attention prior to onset of tetanus.
Five received a dose of tetanus toxoid, two of whom also received antibiotics; four had injuries that underwent debridement two of whom also received antibiotics, and two only received antibiotics. Other treatments at the time of injury included suturing of wounds and diazepam; none were reported as having received immunoglobulin.

Treatment on presentation with clinical tetanus was known for 74 cases. Most $(98 \cdot 6 \%, n=73)$ received either tetanus immunoglobulin or human normal immunoglobulin (Table 3). Two cases also received a dose of tetanus toxoid alongside immunoglobulin. One case, known to be unimmunized, did not receive tetanus toxoid or immunoglobulin on presentation.

\section{Severity of disease}

Where the severity of clinical tetanus was known $55 \cdot 8 \%(48 / 86)$ were classified as severe (grade $3 a / 3 b$ ), a further $31.4 \%(27 / 86)$ had mild (grade 1) tetanus, and $12.8 \%(11 / 86)$ had moderate (grade 2$)$ tetanus (Tables 3 and 4). In total, 66.3\% (55/83) of all cases were known to have been admitted to an intensive treatment unit (ITU). When severity was known (67.1\%, 53/79), 18.5\% (5/27) of cases with mild tetanus were admitted compared to $80 \cdot 0 \%(8 / 10)$ with moderate tetanus, and $95 \cdot 2 \%(40 / 42)$ with severe tetanus.

Using ordered logistic regression there was no association between the severity of clinical tetanus and gender $(P=0.716)$ nor immunization status $(P=$ $0 \cdot 890)$, whereas age and admission to ITU were both associated with increased severity $(P=0.028$ and $P<0 \cdot 001)$. When a multivariate model adjusted for immunization status was used, age was no longer significant $(P=0 \cdot 125)$. The median duration of illness was 26 (IQR 7-55, range 1-131) days and cases with 
Table 3. Severity of disease, immunization status and type of injury in tetanus cases with follow-up information 2001-2014 ( $n=96)$

\begin{tabular}{|c|c|c|}
\hline & $\begin{array}{l}\text { No. of } \\
\text { cases }\end{array}$ & $\begin{array}{l}\% \\
\text { known }\end{array}$ \\
\hline \multicolumn{3}{|l|}{ Immunization status at time of injury } \\
\hline Unimmunized & 28 & $41 \cdot 2$ \\
\hline Partially immunized & 34 & $50 \cdot 0$ \\
\hline Age appropriately immunized & 6 & $8 \cdot 8$ \\
\hline $\begin{array}{l}\text { Vaccination history not known or not } \\
\text { reported }\end{array}$ & 28 & \\
\hline \multicolumn{3}{|l|}{ Setting of injury/exposure } \\
\hline Garden/home & 45 & $70 \cdot 3$ \\
\hline Street/road & 8 & $12 \cdot 5$ \\
\hline Work & 3 & $4 \cdot 7$ \\
\hline Park/woodland/rural & 2 & $3 \cdot 1$ \\
\hline Other & 6 & $9 \cdot 4$ \\
\hline Reported injury but details unknown & 9 & \\
\hline No signs or history of injury & 8 & \\
\hline Not known & 15 & \\
\hline \multicolumn{3}{|l|}{ Type of injury/exposure } \\
\hline Animal bite/scratches & 5 & $6 \cdot 8$ \\
\hline Burn/ulcer & 3 & $4 \cdot 1$ \\
\hline Laceration & 29 & $39 \cdot 7$ \\
\hline Puncture wound & 36 & $49 \cdot 3$ \\
\hline Injection site & 21 & $28 \cdot 8$ \\
\hline No signs or history of injury & 8 & \\
\hline Not known & 15 & \\
\hline \multicolumn{3}{|l|}{ Injecting drug use } \\
\hline Reported injecting drug usage & 31 & $40 \cdot 3$ \\
\hline No reported injecting drug usage & 46 & $59 \cdot 7$ \\
\hline Not known & 19 & \\
\hline \multicolumn{3}{|l|}{ Treatment at time of injury* } \\
\hline Any treatment at time of injury & 16 & $29 \cdot 1$ \\
\hline Tetanus toxoid & $5 \dagger$ & $31 \cdot 3$ \\
\hline Tetanus immunoglobulin & 0 & $0 \cdot 0$ \\
\hline Antibiotics & $5 \ddagger$ & 3 \\
\hline Debridement & 4 & $25 \cdot 0$ \\
\hline Other treatment & 5 & $31 \cdot 3$ \\
\hline No treatment & 39 & $70 \cdot 1$ \\
\hline Not known & 41 & \\
\hline \multicolumn{3}{|l|}{$\begin{array}{l}\text { Treatment on presentation with } \\
\text { suspected clinical tetanus* }\end{array}$} \\
\hline Tetanus toxoid & 2 & $2 \cdot 7$ \\
\hline $\begin{array}{l}\text { Tetanus or human normal } \\
\text { immunoglobulin }\end{array}$ & 73 & $97 \cdot 3$ \\
\hline No treatment & 1 & \\
\hline Not known & 22 & \\
\hline \multicolumn{3}{|l|}{ Hospital admission } \\
\hline Yes: Intensive treatment unit & 55 & $66 \cdot 3$ \\
\hline Yes & 26 & $31 \cdot 3$ \\
\hline No & 2 & $2 \cdot 4$ \\
\hline Not known & 13 & \\
\hline \multicolumn{3}{|l|}{ Severity of disease } \\
\hline Grade 1 & 27 & $31 \cdot 4$ \\
\hline Grade 2 & 11 & $12 \cdot 8$ \\
\hline Grade 3 & 48 & $55 \cdot 8$ \\
\hline Not known & 10 & \\
\hline
\end{tabular}

Table 3 (cont.)

\begin{tabular}{|c|c|c|}
\hline & $\begin{array}{l}\text { No. of } \\
\text { cases }\end{array}$ & $\begin{array}{l}\% \\
\text { known }\end{array}$ \\
\hline \multicolumn{3}{|l|}{ Outcome at time of follow-up } \\
\hline Died & 9 & $11 \cdot 0$ \\
\hline Recovered & 42 & $51 \cdot 2$ \\
\hline Partial recovery, still ill and in-patient & 31 & $37 \cdot 8$ \\
\hline Not known & 14 & \\
\hline Total & 96 & \\
\hline
\end{tabular}

* Cases may have received more than one intervention.

$\dagger$ An additional case received tetanus toxoid several days after injury.

+ An additional case received antibiotics several days after injury.

Table 4. Severity of disease and immunization status in tetanus cases with follow-up information 2001-2014 $(n=92)$

\begin{tabular}{|c|c|c|c|c|}
\hline \multirow[b]{2}{*}{$\begin{array}{l}\text { Vaccination } \\
\text { history }\end{array}$} & \multicolumn{4}{|c|}{ Severity (deaths) } \\
\hline & $\begin{array}{l}\text { Grade } \\
1 \text { (mild) }\end{array}$ & $\begin{array}{l}\text { Grade } 2 \\
\text { (moderate) }\end{array}$ & $\begin{array}{l}\text { Grade } 3 \\
\text { (severe) }\end{array}$ & $\begin{array}{l}\text { Not } \\
\text { known }\end{array}$ \\
\hline Unimmunized & 7 & 2 & $16(2)$ & 3 \\
\hline $\begin{array}{l}\text { Partially } \\
\text { immunized }\end{array}$ & $10(1)$ & 3 & $21(3)$ & 0 \\
\hline $\begin{array}{l}\text { Age appropriately } \\
\text { immunized }\end{array}$ & 5 & 0 & 1 & 0 \\
\hline $\begin{array}{l}\text { Vaccination } \\
\text { history not } \\
\text { known or not } \\
\text { reported }\end{array}$ & 5 & 6 & $10(2)$ & $3(1)$ \\
\hline Total & 27 (1) & 11 & $48(7)$ & $6(1)$ \\
\hline
\end{tabular}

severe clinical tetanus had a longer illness than those with mild tetanus (median 42 vs. 7 days; $z=-3.93$, $P>0 \cdot 001$ ).

The final outcome was known for 52 cases, 43 of whom were discharged from hospital. The ages of the nine cases known to have died ranged from 47 to 91 years. Seven had severe tetanus and one was reported as having mild tetanus; the severity of tetanus was not recorded in one case. Seven had a history of injury, four sustained lacerations in the home/garden, one sustained a puncture wound while walking in a semi-rural area, one had an infected injection site, and one had been scratched by a companion animal but had also reported feeling unwell prior to the incident. Three died within a week of onset of illness all of whom had severe tetanus, one case-patient 
died within 1 month, three died within 3 months, and the duration of illness was not recorded in two cases. The overall case-fatality rate for tetanus was $11.0 \%$ ( 9 / 96).

A further 31 cases were still in hospital at the time of the last follow-up and no additional information was received; however, as all death certifications with mention of tetanus (either as a direct cause of death or tetanus-related) were examined for matches in the years 2001-2014 and none were identified suggesting that none of these cases died as a result of their infection.

\section{Tetanus in PWID}

A total of 31 cases had a known history of injecting drug usage, the majority $(n=22)$ of whom acquired tetanus during a cluster of infections in 2003-2004 (Table 2, Fig. 2) [19]. In the study period, PWID cases were reported in all regions of England (range $1-7$ cases), with $58 \cdot 1 \%$ cases reported in men. Their ages ranged from 20 to 53 (median age 36, IQR 2847) years with no significant difference between males and females ( 37.5 vs. 33.0 years, respectively, $P=0 \cdot 245$ ). The median age of PWID was, however, 25 years younger than that of non-PWID cases (median 61, IQR 41-80 years, $P<0 \cdot 001$ ). Fifteen PWID were reported as having an infected injection site, a further four had a history of injury of which two could have been related to injecting practices, one to a fall and the other to a dog bite.

In the subgroup of PWID who acquired tetanus during the 2003-2004 outbreak 59.1\% $(n=13 / 22)$ were male. Cases ranged in age from 20 to 50 (median $34 \cdot 0$ ) years. The median age of male PWID was 38 years compared to a median age of 22 years for females $(P=0 \cdot 071)$. Fourteen were reported as having injected within the past month, only four of whom had a specific injury recorded, the remaining eight had unknown injury status.

\section{HES data/data matching}

During the fiscal years 2001/2002 to 2010/2011, there were a total of 400 hospital episodes recorded with a diagnostic code of tetanus, obstetric tetanus, or tetanus neonatorum. These episodes related to 238 patients. On review, data for 117 patients were assessed as not having tetanus and were excluded. Of the remaining 121 patients, $54(44 \cdot 6 \%)$ were

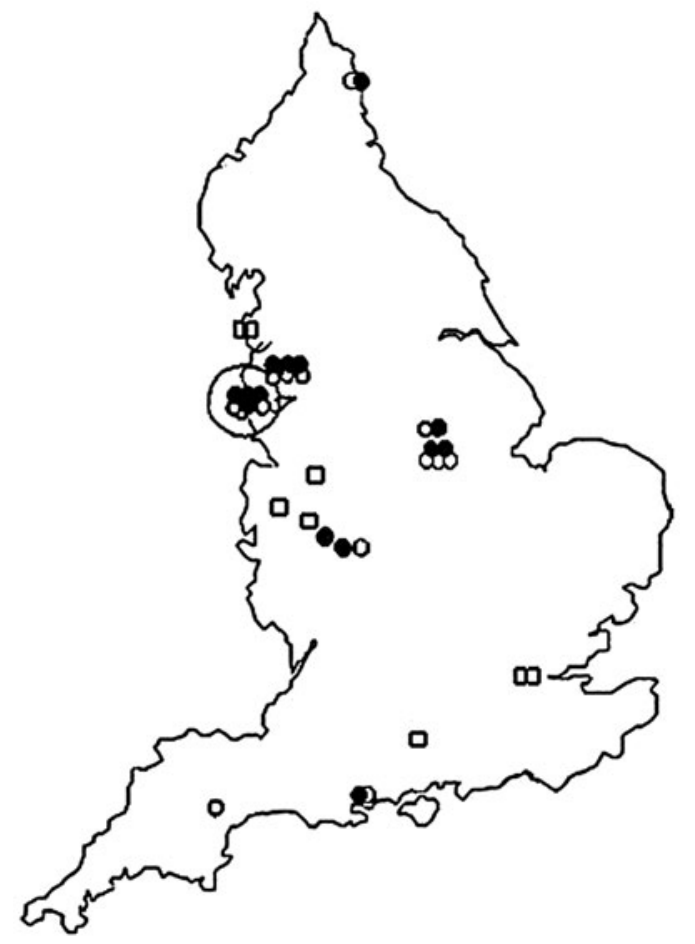

Fig. 2. Map of tetanus cases in people who inject drugs, 2003-2004 data.

matched to a case reported to the enhanced surveillance programme (Table 5, Fig. 3).

The proportion of males identified through the HES dataset was similar to the enhanced surveillance dataset. Overall, $46 \cdot 3 \%$ of patients with tetanus known to HES were male compared to $50 \cdot 3 \%$ for enhanced surveillance $(P=0 \cdot 547)$. The median age of patients in the HES dataset was $43 \cdot 1$ years, with no statistical difference in the median age of males compared to females (42.6 vs. 43.1 years, $P=0.854$ ); however, this was nearly 4 years younger than those reported to enhanced surveillance $(P=0 \cdot 04)$.

The median duration of a hospitalized episode was 5 (IQR 0-50) days, which was significantly shorter than the median duration of illness in cases in the enhanced surveillance dataset $(P=0 \cdot 042)$. The three patients recorded as having died were matched to the enhanced surveillance dataset.

\section{DISCUSSION}

Notifications of rare infections are known to be incomplete and enhanced surveillance programmes which utilize multiple data sources have been used, particularly for vaccine-preventable infections, for many years [2]. PHE's enhanced tetanus surveillance 
Table 5. Number of case-patients with tetanus reported by hospital episode statistics (HES) per year and proportion matched to surveillance data

\begin{tabular}{llllll}
\hline \hline Year & $\begin{array}{l}\text { No. of case-patients } \\
\text { known to HES }\end{array}$ & $\begin{array}{l}\text { No. of case-patients } \\
\text { known to surveillance }\end{array}$ & $\begin{array}{l}\text { No. matched } \\
\text { between datasets }\end{array}$ & $\begin{array}{l}\text { \% HES matched to } \\
\text { surveillance }\end{array}$ & $\begin{array}{l}\text { \% surveillance } \\
\text { matched to HES }\end{array}$ \\
\hline 2001 & 7 & 4 & 3 & $42 \cdot 9$ & $75 \cdot 0$ \\
2002 & 8 & 5 & 4 & $50 \cdot 0$ & $80 \cdot 0$ \\
2003 & 12 & 12 & 8 & $66 \cdot 7$ & $66 \cdot 7$ \\
2004 & 33 & 22 & 18 & $54 \cdot 5$ & $81 \cdot 8$ \\
2005 & 8 & 5 & 4 & $50 \cdot 0$ & $80 \cdot 0$ \\
2006 & 10 & 3 & 0 & $0 \cdot 0$ & $0 \cdot 0$ \\
2007 & 8 & 4 & 3 & $37 \cdot 5$ & $75 \cdot 0$ \\
2008 & 15 & 4 & 3 & $20 \cdot 0$ & $75 \cdot 0$ \\
2009 & 12 & 7 & 6 & $50 \cdot 0$ & $85 \cdot 7$ \\
2010 & 8 & 10 & 5 & $62 \cdot 5$ & $50 \cdot 0$ \\
Total & $\mathbf{1 2 1}$ & $\mathbf{7 6}$ & $\mathbf{5 4}$ & $\mathbf{4 4 \cdot 6}$ & $\mathbf{7 1 \cdot 1}$ \\
\hline \hline
\end{tabular}

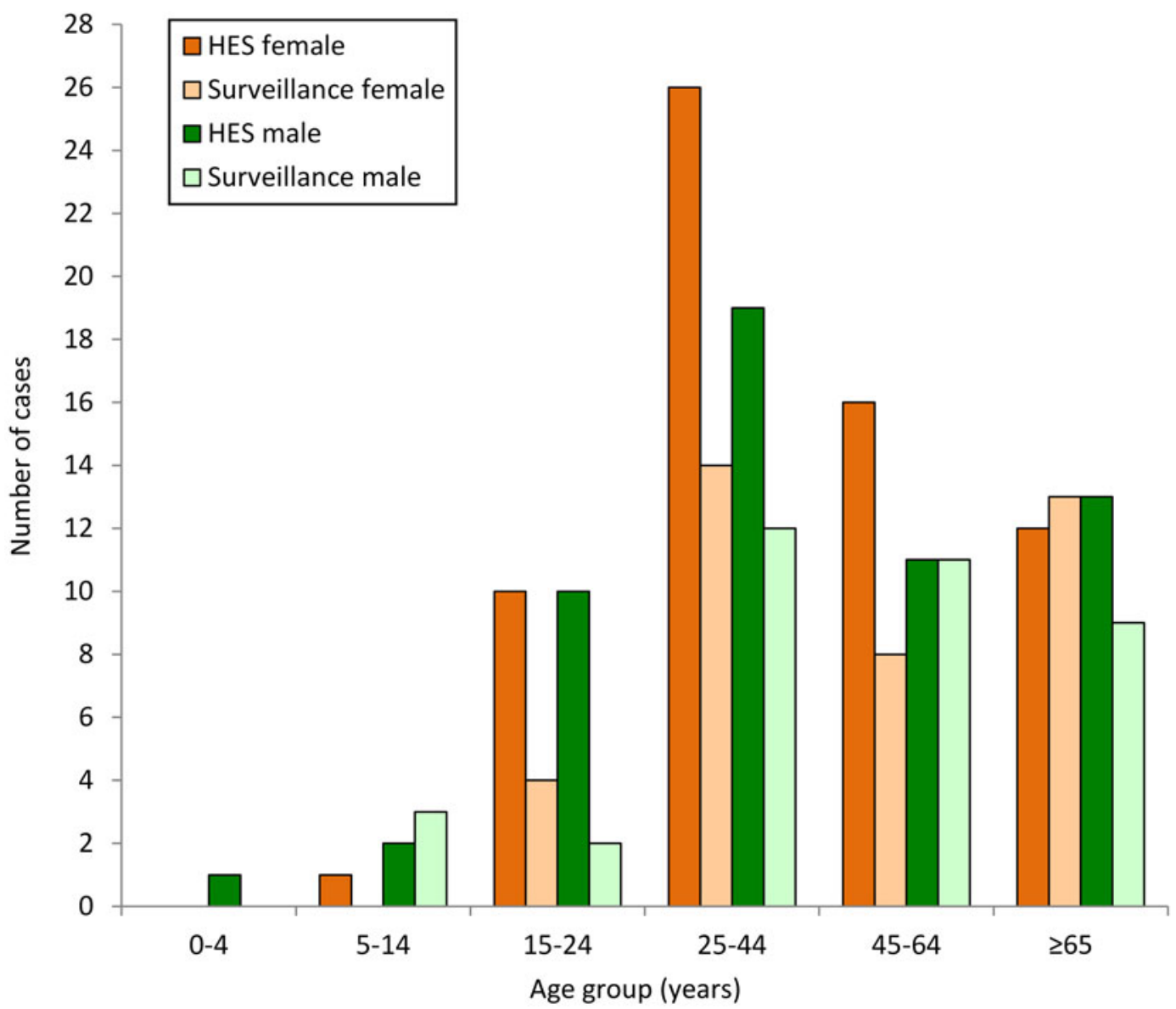

Fig. 3. Number of case-patients with tetanus known to hospital episode statistics (HES) and enhanced surveillance by age group and gender, 2001-2010 data.

programme uses statutory notifications, clinical enquires, microbiological services, and ONS death data to identify suspected cases of clinical tetanus. For this review we have also retrospectively examined hospital admissions coded as tetanus or tetanusrelated disease. This approach has improved the ascertainment of cases and leads to a more complete picture of tetanus in England than would otherwise 
be available. Between 2001 and 2014, relatively few cases of tetanus were identified per year, reflecting the consistently high vaccine coverage achieved over several decades increasing the proportion of the population protected against tetanus. However, as there is no herd immunity effect provided by immunization against tetanus $[1,6]$ it is important high coverage is maintained and that appropriate surveillance systems are in place to monitor any changes in vaccine coverage, incidence or case-fatality rates.

As reported previously, there is no longer a difference in incidence of tetanus according to gender as was observed in the mid to late 20th century [4]. Until the 1980s, the incidence of tetanus was lower in males, due in part to the number of men who received immunizations during their National Service and/or presenting with tetanus-prone wounds receiving tetanus toxoid vaccine. Results from a recent seroprevalence survey indicate that at a population level males still have a higher level of anti-tetanus immunoglobulin $G$ than females, conferring a greater immunity to tetanus in males [9]. However, this may be counterbalanced by the fact that the incidence of injuries is greater in men than women for most age groups [20] and it may be that more men than women acquire tetanus-prone injuries, increasing the likelihood of a susceptible male becoming inoculated with $C$. tetani. The proportion of cases in those who were eligible for routine childhood vaccination was higher than previously reported between 1984 and $2000(47 \%$ vs. $11 \%)$ [4]. The median age of cases in the period 2001-2014 was influenced by the outbreak of tetanus in PWID in 2003 and 2004, as reported in more detail at the time $[19,21]$. This outbreak was unusual for England and for Europe as a whole [22], but tetanus is more commonly reported in PWID in the United States, particularly in California, where the injection of home-refined 'black tar' heroin is often implicated [23]. English PWID with tetanus were significantly younger than those who did not inject drugs and this lowered the median age of the overall population who acquired clinical tetanus. It is apparent that young adults who have not received the recommended course of immunizations are at risk of acquiring tetanus with or without the additional risk factor of injecting drugs. Opportunities for those individuals who are currently unimmunized or partially immunized to complete their course should be enhanced; particularly in healthcare services accessed by PWID, and appropriate advice provided about the prevention of tetanus and other clostridial infections investigated [24].
The completeness of follow-up information obtained as part of enhanced surveillance has increased over time with additional information available for every case since 2005. There have been improvements in the level of information recorded by local health protection teams through the use of computerized casemanagement tools and in the communication between local and national microbiology services, and local and national health protection teams.

The majority of cases had a recorded injury prior to the onset of clinical tetanus, and most were injuries that occurred while at home or in the garden. Inoculation with tetanus spores from contaminated soil through lacerations and puncture wounds, via rusty nails or animal contact remain the most common routes of acquiring tetanus. From our data, most injuries were minor, and where known, the majority $(70 \%)$ of cases did not seek treatment at the time of injury. This may be due to a lack of awareness by the public of both the risk of acquiring tetanus following minor injuries if not fully vaccinated, and knowledge of their tetanus immunization status. During follow-up it became apparent that cases were frequently unsure of the details of their tetanus immunizations which is consistent with other studies [25]. This lack of knowledge may be a barrier to cases accessing prophylaxis for what may be considered a minor injury. Our study also showed that GP immunization records for older patients were often incomplete. Awareness-raising by general practice and in accident and emergency departments may increase the likelihood of individuals seeking and receiving treatment [26]. However, clinicians in an accident and emergency department may not have access to a patient's immunization history which increases the uncertainty when performing a risk assessment prior to issuing prophylaxis.

Given the small number of cases who sustained injuries while at work, and high levels of immunity in the working-age population, it is difficult to ascertain the current role of occupational health departments in advising case-patients about the risk of tetanus-prone wounds, and efforts to ensure the workforce is fully vaccinated may be more appropriate.

The case-fatality rate for tetanus was lower than that reported previously, and where the final outcome was known, was $25 \%$ for cases with severe tetanus compared to $39 \%$ recorded previously [2]. However, assuming no deaths due to tetanus went unrecorded in this group, the case-fatality rate could be as low as $15 \%$ in those with severe tetanus. The increased 
survival of severe tetanus may be due to improved case management.

As with other rare diseases, formal notification of clinical tetanus was poor, and enhanced surveillance is required to identify additional cases though other data sources [4]. The matching exercise between HES and enhanced surveillance datasets identified 67 additional cases of tetanus. This would suggest tetanus is currently underreported by $88 \%$, higher than in the previous analysis [4]. The level of matching varied by age group, with a greater proportion of working-age women appearing in the HES dataset compared to enhanced surveillance. It is probable that some of those patients in the HES dataset did not have clinical tetanus but were erroneously coded following tetanus-prone injuries.

\section{CONCLUSIONS}

As tetanus becomes increasingly rare the likelihood of a clinician treating an individual presenting with clinical tetanus decreases. Partially immunized patients may present with very mild tetanus, which may not immediately prompt clinicians to think of tetanus as one of the differential diagnoses. Although this could potentially be a source of bias with the more severe cases more likely to be identified and recorded, our data show an increase in the number of cases with mild (grade 1) tetanus, consistent with a relative increase in the number of infections in younger, partially immunized cases. In an era when vaccination coverage has been consistently high and most people are protected against tetanus, maintaining awareness of the potential threat to the minority of underimmunized cases is a challenge.

\section{ACKNOWLEDGEMENTS}

We thank our colleagues in the local Health Protection Teams for help with collection of surveillance data. We thank the all of the clinicians and other staff who were involved in the management of these cases and who provided enhanced surveillance data. We also thank Kathie Grant and Corinne Amar in the Gastrointestinal Bacteria Reference Unit for their comments on these cases and help in interpreting laboratory data. N.J.B. receives support from the NIHR-funded Health Protection Research Unit in Emerging and Zoonotic Infections, a partnership between the University of Liverpool, Public Health England and the Liverpool School of
Tropical Medicine. The views expressed are those of the author(s) and not necessarily those of the NHS, the NIHR, the Department of Health or Public Health England.

This study received no external funding.

\section{DECLARATION OF INTEREST}

None.

\section{REFERENCES}

1. Duerden BI, Brazier JS. Tetanus and other clostridial diseases. Medicine 2009; 37: 638-640.

2. Farrar JJ, et al. Tetanus. Journal of Neurology, Neurosurgery \& Psychiatry 2000; 69: 292-301.

3. Thwaites CL, Farrar JJ. Preventing and treating tetanus. British Medical Journal 2003; 326: 117-118.

4. Rushdy AA, et al. Tetanus in England and Wales, 1984 2000. Epidemiology \& Infection 2003; 130: 71-77.

5. Thwaites CL, Beeching NJ, Newton CR. Maternal and neonatal tetanus. Lancet 2015; 385: 362-370.

6. Public Health England. Chaper 30: Tetanus. 2013 (https://www.gov.uk/government/publications/tetanus-thegreen-book-chapter-30).

7. Public Health England. Chapter 11: The UK immunisation programme. 2014 (https://www.gov.uk/ government/publications/immunisation-schedule-the-greenbook-chapter-11).

8. Health and Social Care Information Centre. NHS Immunisation Statistics, England - 2014-15. 2015 (https:// www.gov.uk/government/statistics/nhs-immunisation-statist ics-england-2014-to-2015)

9. Wagner KS, et al. Immunity to tetanus and diphtheria in the UK in 2009. Vaccine 2012; 30: 7111-7117.

10. Public Health England. Notifications of Infectious Diseases (NOIDs). 2014 (https://www.gov.uk/govern ment/collections/notifications-of-infectious-diseases-noids).

11. Public Health England. Bacteriology reference department (BRD): user manual. 2014 (https://www.gov.uk/ government/publications/bacteriology-reference-depart ment-brd-user-manual).

12. Public Health England. Tetanus immunoglobulin: recommendations on treatment and prophylaxis. 2013 (https://www.gov.uk/government/publications/tetanusimmunoglobulin-recommendations-on-treatment-andprophylaxis).

13. Public Health England. Recommendations on the treatment and prophylaxis of tetanus. 2015 (https://www. gov.uk/government/uploads/system/uploads/attachment_ data/file/441358/IMW163.02_Recommendations_on_the_ treatment_and_prophylaxis_of_tetanus_v1_5.pdf).

14. Office for National Statistics. Primary Care Organisation Population Estimates (experimental)-Mid-2006. 2010 (http://www.ons.gov.uk/ons/rel/sape/pco-pop-est-exp/mid2006-release/index.html).

15. NHS the Information Centre for Health and Social Care. The Hospital Episode Statistics user guide. 2010. 
16. Cook TM, Protheroe RT, Handel JM. Tetanus: a review of the literature. British Journal of Anaesthesia 2001; 87: 477-87.

17. Research Development and Statistics Directorate. Measuring different aspects of problem drug use: methodological developments, 2006.

18. Begg NT, Gill ON, White JM. COVER (cover of vaccination evaluated rapidly): Description of the England and Wales scheme. Public Health 1989; 103: 81-89.

19. Hahné SJ, et al. Tetanus in injecting drug users, United Kingdom [Letter]. Emerging Infectious Diseases 2006; 12: 709-710.

20. White A, De Sousa B, De Visser R et al. Men's health in Europe. Journal of Men's Health 2011; 8: 192-201.

21. Beeching NJ, Crowcroft NS. Tetanus in injecting drug users. British Medical Journal 2005; 330: 208-209.
22. Hope VD, et al. A decade of spore-forming bacterial infections among European injecting drug users: pronounced regional variation. American Journal of Public Health 2012; 102: 122-125.

23. Pascual FB, et al. Tetanus Surveillance - United States, 1998-2000. Morbidity and Mortality Weekly Report 2003; 52: 1-8.

24. Public Health England. Tetanus: advice for people who inject drugs. 2013 (https://www.gov.uk/government/ publications/tetanus-advice-for-people-who-inject-drugs).

25. Savage EJ, et al. Audit of tetanus prevention knowledge and practices in accident and emergency departments in England. Emergency Medicine Journal 2007; 24: 417-421.

26. Collins $\mathbf{S}$, et al. The importance of tetanus risk assessment during wound management. IDCases 2015; 2: 3-5. 